\title{
Motorcycle recycling flow and end-of-life motorcycles in Japan
}

\author{
Mami Kimura' ${ }^{1} \cdot$ Takumi Yamane $^{2}$
}

Received: 2 June 2021 / Accepted: 18 October 2021 / Published online: 31 October 2021

(c) The Author(s) 2021

\begin{abstract}
This study compiled the number of End-of-Life motorcycles (ELMCs), utilizing Japanese official motorcycle data to clarify "the characteristics of distribution flow and main actors" of ELMCs. Based on its results, domestic ELMCs were estimated at approximately between 500,000 and 600,000 annually. The exact ELMCs number in 2019 was 521,644, 81.4\% of which were exported. The ratio of exported used motorcycles among these ELMCs was analyzed and categorized according to engine discharge. Accordingly, the analysis showed that motorcycles with $50 \mathrm{cc}$ and less total emissions had a high proportion, $62.8 \%$, of the total in 2019. New insights from this study include (1) the characteristics of the used motorcycle distribution flow in Japan and that they are eventually exported and (2) the main actors in the distribution flow are used motorcycle auction sites that assume a leading role in recycling motorcycles domestically and internationally.
\end{abstract}

Keywords End-of-life motorcycles · Voluntary recycling system · Exported used motorcycle

\section{Introduction}

This study aims to clarify "the characteristics of distribution flow and main actors" of ELMCs by compiling official Japanese motorcycle data, including the number of motorcycles domestically owned, sold, and trade statistics.

Numerous studies on domestic distribution flow and recycling systems for end-of-life vehicles have been conducted in Japan. However, few studies have been conducted on domestic recycling flow and recycling systems for ELMCs. Some previous ELMCs studies in Japan include Yoneyama and Matsumoto [1], Abe and Kimura [2], and Kimura and Asazuma [3]. Moreover, Hara [4] studied official data relative to motorcycles in Japan, such as amounts domestically owned and sold. In addition, Murakami et al. [5] studied the future generation of used motorcycles.

Yoneyama and Matsumoto [1] emphasized "design studies on recycling systems" and clarified the compendium and achievement of the voluntary motorcycle recycling system

Mami Kimura

kimura29831@gmail.com

1 Faculty of Environmental Studies, Tokyo City University, Tokyo, Japan

2 Graduate School of Environment and Information Sciences Master's Program, Tokyo City University, Tokyo, Japan
(VRS) administered in 2004. They also highlighted the system's problems. They investigated the actual distribution condition 5 years after the system's implementation proved significantly greater numbers of used motorcycles were reused rather than disposed of. They noted three problems related to the operation of the VRS in the reused market-the primary conduit for exporting used motorcycles, predominantly among ELMCs. First, if the reused market is greater than the disposal market, numbers of disposals in this system does not increase unless end users are forced to dispose of them. Second, if there is no increase in the collected motorcycles, it is inevitable that recycling facilities would be consolidated based on their performance. Third, once used motorcycles are exported, the final disposal method at the end-of-life stage cannot be restricted, so manufacturers should reduce the environmental impact of their products and provide products that are suitable for the existing treatment and recycling infrastructure in the exporting country [1].

Since the study conducted by Yoneyama and Matsumoto [1] only analyzed the year 2008, it is uncertain whether the characteristic of distribution flow continues to be exports in Japan. Their study also indicates the recycling insufficiency in destination countries for exports from the large number of exported used motorcycles; however, the actual routing is uncertain. 
Abe and Kimura [2] and Kimura and Asazuma [3] conducted an "analytic study based on official data", relating to limits that Yoneyama and Matsumoto [1] studied. These studies implemented official data obtained from the Japan Automobile Manufacturers Association (JAMA), the National Federation of Mini Vehicle Associations, and the Japan Automobile Importers Association (JAIA), and highlighted the flow of ELMCs to identify characteristics of distribution flow and export trends. Their results indicated that annual numbers of registered deletions were approximately 600,000 , among which the number of exported used motorcycles was approximately 400,000 , the number of used motorcycles collected in the VRS was approximately 3000, and the number of disposed motorcycles was approximately 200,000. Class $150 \mathrm{cc}$ and less motorized bicycles comprised most exported used motorcycles [2, 3].

Some aspects of the official, data-driven, analytic study remain obscure, namely:

1. Primary reasons that led the distribution flow structure to the export trend, that is, "main actors" in the recycling flow

2. Conditions in the country of destination

3. Relevant accuracy between estimated official data-driven ELMCs and factual numbers

4. The incapability of estimating future potential ELMCs

Several studies have been published regarding limits in official data-driven analytics. For example, Hara [4] examined the third obscure point mentioned above to determine if the official data reflected factual numbers of motorcycles. His study concluded that, for certain types not subject to inspection, official data listing the numbers of these motorcycles owned in Japan greatly exceeded those previously assumed [4].

Regarding the incapability to estimate future potential ELMCs, since the official data-driven analytic study estimated ELMCs based on historical data of motorcycles owned and the number of annually registered and exported used motorcycles, they could not predict future numbers. Murakami et al.'s [5] "study on forecasting discarded motorcycle numbers" focused on Vietnam and estimated future potential numbers of discarded motorcycles. They also indicated the capacity and economic efficiency of intermediate treatment facilities needed in the future by analyzing the composition of motorcycles [5].

As mentioned above, factors that remain unclear in ELMCs studies are "main actors" in the distribution flow and destination country conditions. Therefore, this study aims to clarify the main actors in the distribution flow. Because this study aims to estimate ELMCs based on historical data on the total numbers of motorcycles owned and sold, future predictions are not part of this study.

\section{Materials and methods}

\section{Road transport vehicle act}

The classification of motorcycles is stipulated in the Road Transport Vehicle Act and the Road Traffic Act. Between these, the Road Transport Vehicle Act relates to motorcycle recycling.

The Road Transport Vehicle Act, Article 2 defines "the road transport vehicles" as "motor vehicles", "motorized bicycles", and "light vehicles". The Enforcement Regulations of the Road Transport Vehicle Act, Article 1 defines the range and specification of "motorized bicycles". In this description, motorcycles (except those with a sidecar) with engine power delivering total emissions of $50 \mathrm{cc}$ and less are stipulated as class 1 motorized bicycles. Those above $50 \mathrm{cc}$ and below $125 \mathrm{cc}$ are stipulated as class 2 motorized bicycles [6,7].

The Enforcement Regulations of the Road Transport Vehicle Act, Article 2, Appended Table 1, classifies "motor vehicles" as standard motor vehicle, small motor vehicle, light motor vehicle, special large motor vehicle, and special small motor vehicle. Motorcycles with a total engine size of $250 \mathrm{cc}$ and less are defined as "light motor vehicles", and motorcycles, except for light motor vehicles (meaning total emissions of $250 \mathrm{cc}$ and above), are defined as "small motor vehicles" [7].

\section{Act on recycling, etc. of end-of-life vehicles}

The Road Transport Vehicle Act is relative to the Act on Recycling, etc. of End-of-Life Vehicles in Japan. This Act ensures that waste from end-of-life vehicles is properly disposed of, and that resources are used effectively by reducing waste from these vehicles, and the recycling procedure of used parts is achieved. This objective is accomplished by requiring vehicle manufacturers and related businesses to collect and deliver end-of-life vehicles and devise ways to recycle them appropriately, thereby contributing to the preservation of the environment and the development of a sound national economy [8].

In this Act, "vehicle" is defined similarly to those described in the Road Transport Vehicle Act, Article 2, Paragraph 2, except the following [8]:

1. Towed vehicles (among the vehicles described in the Road Transport Vehicle Act, Article 2, Paragraph 2, are those manufactured to tow other vehicles)

2. Compact vehicles and light vehicles described in the Road Transport Vehicle Act, Article 3 (except towed vehicles) and two-wheel vehicles (including those with a sidecar) 
3. Large and small custom-made vehicles (except towed vehicles) are described in the Road Transport Vehicle Act, Article 3

\section{Voluntary motorcycle recycling system (VRS)}

The Act on Recycling, etc., of End-of-Life Vehicles was enforced in 2005, but motorcycles were not subject to this legislation, because, when compared to other vehicles (hereafter referred to as four-wheeled vehicles), motorcycles had a greater export volume. Furthermore, fewer motorcyclespecialized recycling businesses existed, motorcycles did not contain fluorocarbons and airbags, and they were managed by notification systems in local governments and district land transport bureaus, differing from registration systems for four-wheeled vehicles [9].

Consequently, motorcycle recycling systems were established as voluntary efforts. In October 2004, four domestic motorcycle manufacturers (Honda Motor, Yamaha Motor, Suzuki Motor, and Kawasaki Heavy Industries), along with 11 importers disbursed funds and initiated a VRS whose duties included establishing certified collection centers and recycling/treatment facilities, and operating and managing recycling networks [10].

Approximately 15,000 registered motorcycle dealers from the National Federation of Mini Vehicle Associations were designated when this system began. One hundred ninety existing nationwide infrastructure facilities from home appliance recycling group A (Matsushita Electric Industrial and others) were designated as certified collection centers. Fourteen existing facilities from this recycling group were designated as recycling or treatment facilities for motorcycles, considering the distance to collection centers [10]. The motorcycle recycling operation at Japan Automobile Recycling Promotion Center (JARC) was commissioned by four domestic motorcycle makers to handle public relations, operate call centers, correspond with local governments, and administer the work [11].
The five main characteristics of a VRS are as follows:

1. Motorcycle manufacturers establish their own or commission collection centers and treatment and recycling facilities

2. Domestic motorcycle manufacturers apply a recycling symbol on motorcycles to be sold in the future

3. When motorcycles sold after implementation of the VRS (these motorcycles should have a recycling symbol attached) are disposed, ELMCs are collected without disposal fees

4. Motorcycles sold before implementation of the VRS (these do not have a recycling symbol attached) are collected without disposal fees 7 years after the VRS implementation (users pay actual costs for those 7 years)

5. The VRS' effectiveness can be improved by structuring it to allow domestic motorcycle manufacturers to cooperate with importers, ensuring importers to easily participate [12].

Figure 1 indicates the flow of ELMCs in the VRS. Users bring motorcycles to certified collection centers or consult registered motorcycle dealers. In the latter, dealers assess whether motorcycles can be reused or should be discarded. Motorcycles with recycling symbols can be recycled without processing fees. Registered dealers then transport ELMCs to certified collection centers. If users entrust dealers to transport their motorcycles to collection centers, users are responsible for paying dealers' transportation costs to collection centers. Certified collection centers then transport ELMCs to recycling or treatment facilities. Motorcycles (motorized bicycles, light motorcycles, and small motorcycles) subject to the VRS are ones that VRS-participated businesses sold domestically, and bicycles (including power-assisted bicycles), all-terrain vehicles (ATVs), buggy cars, and products other than motorcycles are not subject to the VRS [11].

The VRS collection structure consists of four entities: user, certified collection center, registered motorcycle dealer, and recycling or treatment facility. However, JARC's
Fig. 1 Flow of ELMCs in VRS [11]

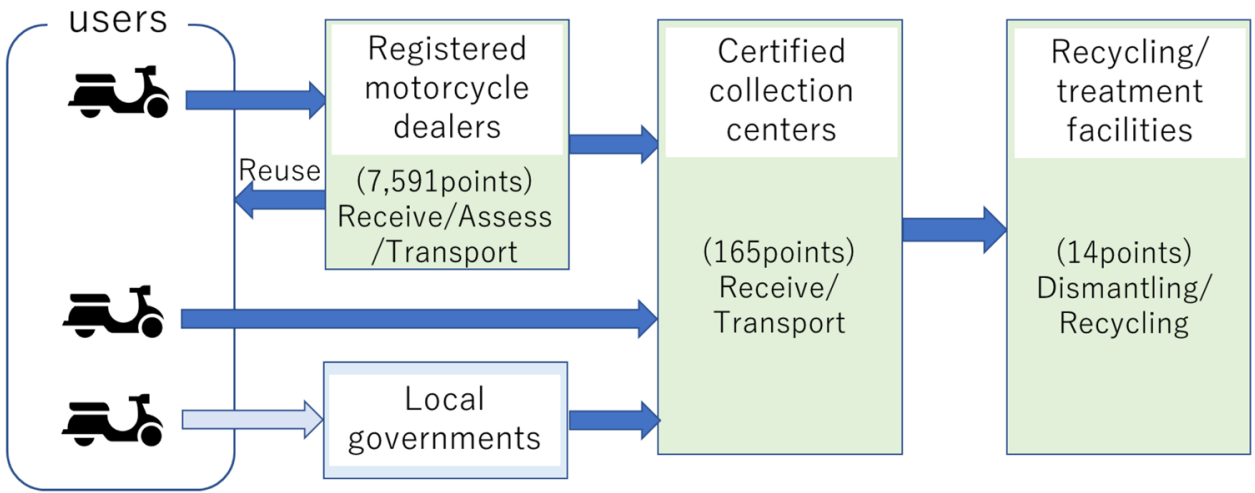


published operation results included the number of motorcycles collected from local governments, thereby considering them indirect VRS participants [11]. As of May 8, 2021, there are 7591 VRS-registered motorcycle dealers, 165 certified collection centers, and 14 recycling or treatment facilities. As of April 1, 2021, eight companies participated in the motorcycle recycling system: Honda Motor, Yamaha Motor, Suzuki Motor, Kawasaki Heavy Industries, EKA, Ducati Japan, BMW Japan, and KYMCO Japan [11].

Figure 2 shows the number of ELMCs collected at certified collection centers. The breakdown of these ELMCs includes numbers collected through registered dealers, submitted by users and collected by local governments. ELMCs collected annually have been between 1670 and 3978, except for 2013 (7168) and 2014 (6524). The rapid increase can be attributed to the Japanese Postal Service discarding 4659 motorcycles in 2013 and 4788 in 2014 through registered dealers. The number collected through registered dealers in 2019 also includes 398 discarded motorcycles from the Japanese Postal Service [11].

The increased numbers from local governments (1793 motorcycles) in 2012 contained 425 motorcycles collected from disaster areas due to the Great East Japan Earthquake. The number of user-brought-in motorcycles (1509) in 2018 included 344 motorcycles collected from areas affected by natural disasters [11].

By examining the varying motorcycle numbers collected, the VRS appears to function as a safety net for sudden collection increases, including from natural disasters and motorcycles discarded by the Japanese Postal Service.

\section{End-of-life motorcycles (ELMCs)}

The meaning of the term "registration" must first be recognized when examining ELMCs estimation methods. As previously stated, because motorcycles are not subject to "registration" in the Road Transport Vehicle Act, the quantum of small motorcycle data is acquired by "inspection" based on the inspection system, and light motorcycles data acquired by "notification" is reported to the Transport Bureau's branch offices to receive license plates [6]. Although a motorcycle registration system is nonexistent, the discarding process is called "deregistration", and new "inspection and notification" are termed "new registered", thus requiring caution when referring to "registration" $[13,14]$. Therefore, this study refers to new or renewed "inspection and notification" to convey "registration" for convenience.

Below, this study examined the number and estimation methods of ELMCs using official data, including numbers of motorcycles owned, sold, and exported. In this study, ELMCs, synonymous with the "number of registered deletions" highlighted by Abe and Kimura [2], calculated with Eq. (1) [2].

ELMCs $=\mathrm{Op}+\mathrm{Rc}-\mathrm{Oc}$

Op: owned units at the end of the previous year. Rc: registered units at the period of the current year. Oc: owned units at the end of the current year.

For Op and Oc in Eq. (1), the study applies the data on the number of units owned, and the number of sold units of Rc, both extracted from the World Motor Vehicle Statistics Annual Report published by the JAMA. The number of units sold in this annual report refers to the units shipped to domestic retail stores [15]. The ELMCs numbers used in Eq. (1) are based on: (1) the number of exported used motorcycles, (2) the number of used motorcycles collected in the VRS, and (3) net increase in deregistered [16]. The number of exported used motorcycles can be obtained from the Ministry of Finance's trade statistics. The number of used motorcycles collected in the VRS can be obtained from the data results published by the JARC $[11,17]$. The net increase
Fig. 2 Number of ELMCs collected at certified collection centers

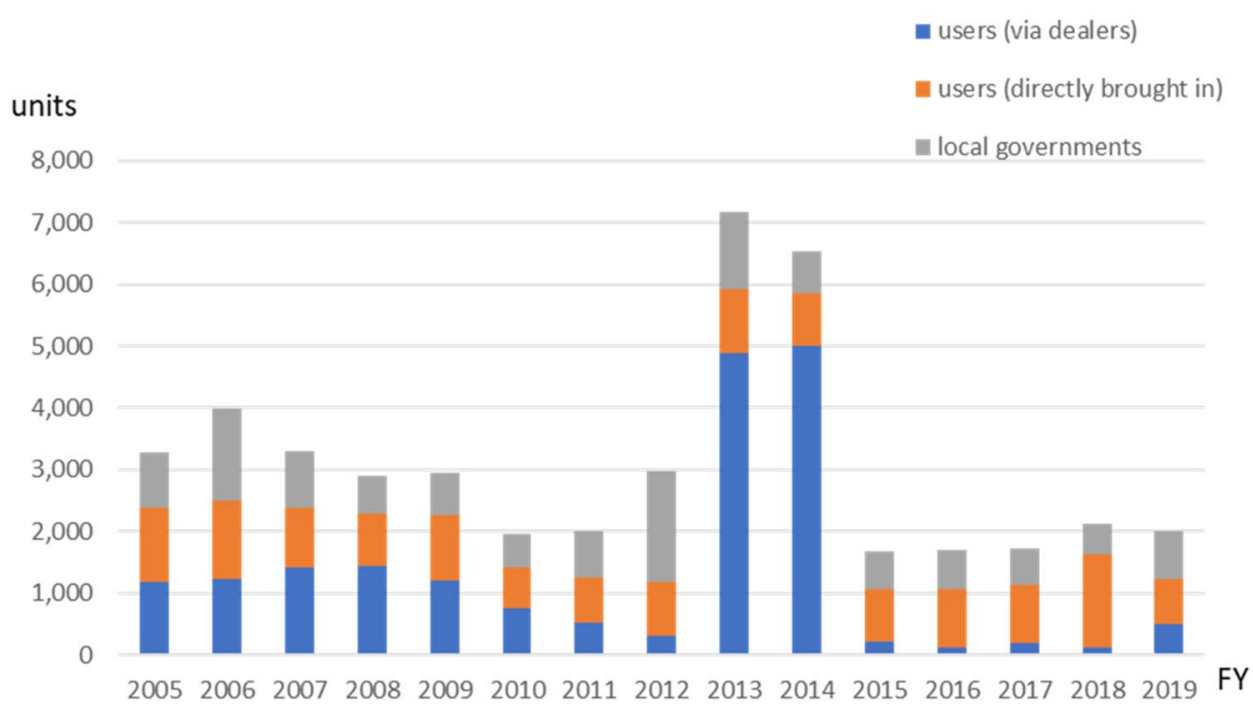


in deregistered motorcycles is difficult to obtain, because no previous data have been published. Consequently, this number is a net increase in the numbers of deregistered and reregistered motorcycles and indicates the number of motorcycles re-registered at the end of the current year among the total registered deletions at the end of the current year and previous years. Presuming that the net increase in the deregistered value, which is minus, was greater than the total number of exported used motorcycles and collected units in the VRS, the amount of ELMCs can be "a minus value" [2].

Before compiling the ELMCs numbers, this study compiled annual registered units and owned units. Accordingly, Fig. 3 shows the number of registered units and owned units from 2005 to 2019. Although 710,158 motorcycles were registered in 2005 , this number gradually declined to 681,610 in 2006 and 655,076 in 2007. Moreover, it rapidly declined to 499,137 in 2008 and 374,482 in 2009. Despite slightly increasing thereafter, the trend remained downward, dropping to 331,156 in 2019. Although the bankruptcy of Lehman Brothers may have been one contributing factor for this rapid decrease in 2009, the direct cause remains uncertain [15].

The number of owned units has also continued to gradually decline. Owned unit numbers of 13,175,176 in 2005 declined to $12,935,182$ in $2007,10,955,960$ in 2017 , and $10,539,849$ in 2019.

Figure 4 shows the ELMCs number calculated with Eq. (1). The same fluctuations as registered units are identified in the ELMCs: 796,681 units in 2005; 646,977 units in 2008; and 486,612 units in 2009. In 2010, the number increased to 577,445 , and since then, the amount has fluctuated in the range of 50,000 to 60,000 . The number in 2019 was 521,644 units $[11,15]$.

In 2005, the percentage of exports within the number of ELMCs was $54.7 \%$ (436,087 units), $60.6 \%(482,693)$ in $2006,65.9 \%(514,565)$ in 2007 , and $66.4 \%(429,755)$ in 2008 . This value reached $70.0 \%(340,815)$ in 2009 , fluctuating in the range of $55.7 \%$ to $76.9 \%$ and reaching the highest percentage of $81.4 \%(424,372)$ in 2019.

The percentage of collected units in the VRS within the number of ELMCs was low, amounting to 0.4\% (3267 units) in 2005 and $0.5 \%$ (3978) in 2006. They were subsequently $1.2 \%$ (7168 and 6524) in 2013 and 2014, respectively, and $0.4 \%$ (2004) in 2019.

The percentage of "net increase in deregistered" among ELMCs was 44.9\% (357,327 units) in 2005, 38.9\% $(309,625)$ in 2006 , and $32.9 \%(262,506)$ in 2007 . It continued to decline to $26.9 \%(214,324)$ in 2008 and $17.9 \%(142,858)$ in 2009. Despite an increase to $26.9 \%$ (214,024 units) in 2010, it rapidly declined to $14.5 \%(115,178)$, and subsequently $12.0 \%(95,268)$ in 2019. The decrease in 2008 and 2009 may be related to the Lehman Brothers' bankruptcy, but factors causing this decrease remain uncertain.

\section{Date adequacy}

The annual report data used in Eq. (1) were reviewed to examine the possible separation from actual conditions. Hara [4] states that the official data for owned unit numbers for any type of vehicle not subject to inspection is overevaluated compared to the precise number. Hara [4] refers to owned unit data from the World Motor Vehicle Statistics
Fig. 3 Number of registered units and owned units

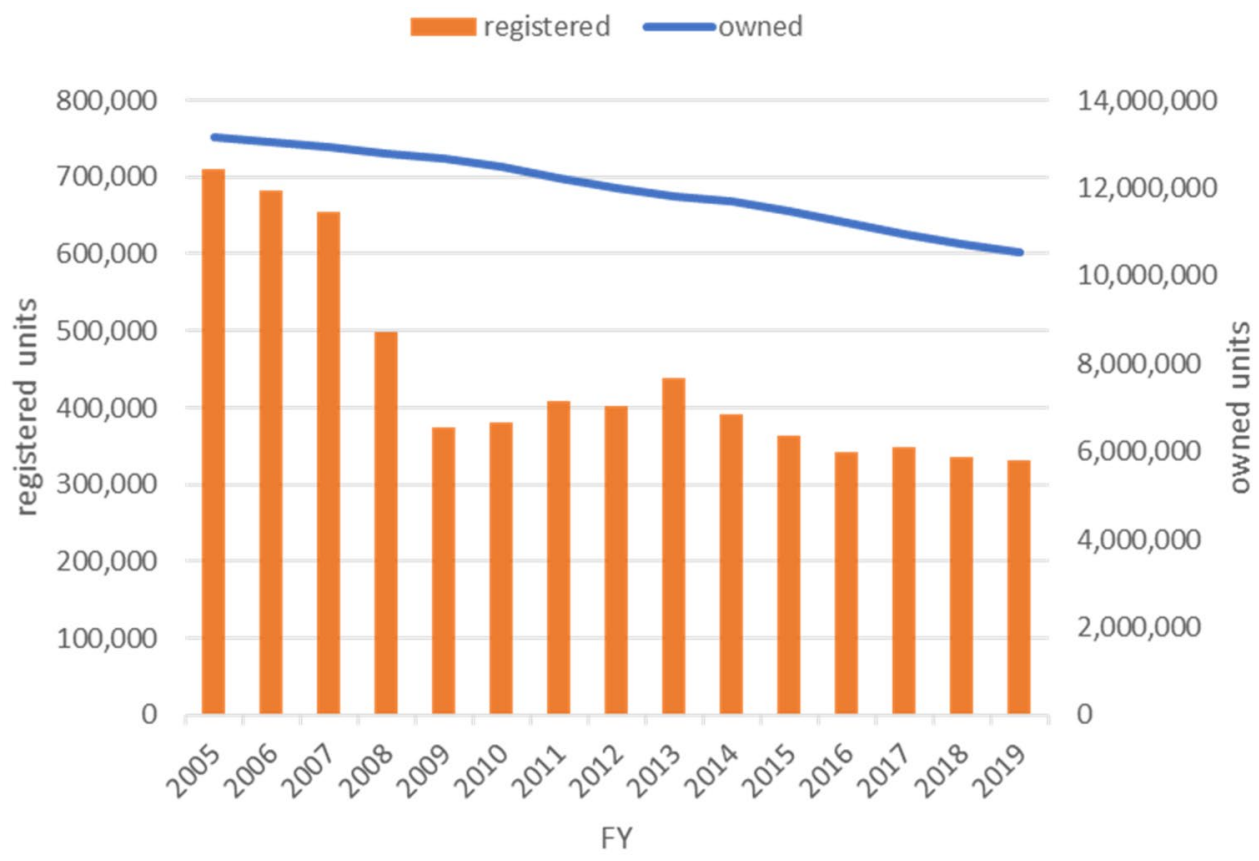


Fig. 4 Number of ELMCs [11, 15]

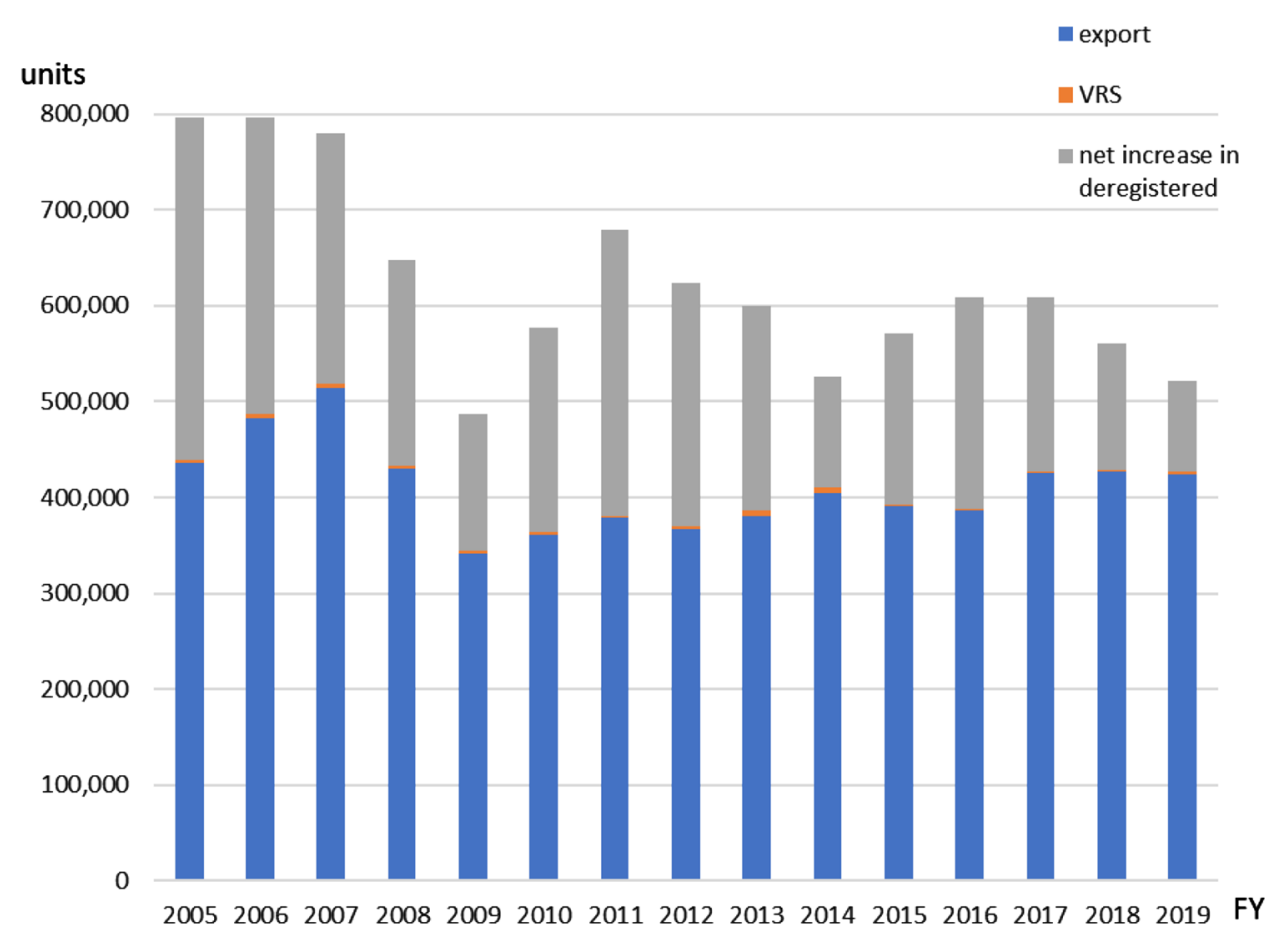

Annual Report as official data. He obtained the numbers of Class 1 and Class 2 motor vehicles from the number of taxed light vehicles and the numbers of light and small motorcycles from the inspection and notification totals published by the Ministry of Land, Infrastructure, Transport and Tourism [4]. First, concerning Class 1 and Class 2 motor vehicles, factual data was applied as the value of the official data for taxable light motor vehicles, and official data were examined to determine its accuracy compared to actual tax payments. Consequently, some taxable motor vehicles are removed from the data if tax payments are overdue for several years, ensuring no conflict between official and factual data [4].

Next, concerning light and small motorcycles, actual data was applied against the number of official data for taxable light motorcycles. After examining this, small motorcycles did not significantly diverge from the official and actual data. However, the results of light motorcycle numbers indicated a value of $80 \%$ less than what was published in the official data, magnifying the conflict probabilities of official and actual data. In addition, the taxable numbers of motorcycles reflect this reality by assuming that "registered deletions are not recorded, but local governments confirmed the disassembled motorcycles and stopped imposing taxes" (p.91) [4].

Furthermore, concerning light motorcycles, the National Survey of Family Income and Expenditure conducted by the Ministry of Internal Affairs and Communications was considered factual data. Therefore, the survey of family income and expenditure-based owned units was approximately $40 \%$ less than the official data, indicating a conflict between the official and factual data [4]. However, as Hara [4] considered a future problem, the National Survey of Family Income and Expenditure referred to targeted households, thus excluding owned units by businesses and organizations and used motorcycle dealers, such as auction sites.

Hara [4] examines the appropriateness of the World Motor Vehicle Statistics Annual Report, which is assumed to be official data, by comparing it with actual data. As he stated as a future problem, the National Survey of Family Income and Expenditure excludes owned units by businesses, organizations and used motorcycle dealers. Hence, it would be difficult to accept Hara's [4] conclusion that the official data for owned units not subject to inspection is over-evaluated compared to the actual number. Then, in this study, the data from the World Motor Vehicle Statistics Annual Report published by JAMA, which is used as official data by Hara [4], is judged to have little possibility of deviation from the actual conditions. Therefore, in Eq. (1), we will use the data from the World Motor Vehicle Statistics Annual Report.

The study also applied sold unit statistics from the same annual report as Rc in Eq. (1). JAMA's sold unit data indicates the shipment volume to domestic retailers, which includes numbers of overseas production re-imported from domestic manufacturers but does not include the overseas manufacturers' import volumes [4]. Kimura and Asazuma [3] obtained the "total domestic sales numbers of light and small motorcycles" produced by overseas manufacturers from the National Federation of Mini Vehicle Association database and also obtained "registered small motorcycle units in the current year" produced by overseas 
manufacturers from the JAIA database. They assumed the difference between these two data sets as "registered light motorcycle units in the current year" and estimated the number of total registered motorcycles at that time. Their result proved that light motorcycles produced by overseas manufacturers increased between 5000 and 20,000 [3]. According to the Kimura and Asazuma's [3] aggregation, JAMA's 2019 data showed sales numbers as 57,656 light motorcycles and 39,890 small motorcycles. The same data also recorded the current-year overseas manufacturer-produced registered light motorcycle units as 10,277 light motorcycles and 20,820 small motorcycles, suggesting that this large proportion of overseas manufactured products should not be ignored. Therefore, the study used data from JAMA for the quantum of sales (shipment volume to domestic retailers). However, there are limitations associated with this data.

\section{Results and discussion}

\section{Characteristics of distribution flow}

As mentioned above, the domestic ELMCs were estimated at approximately 500,000 to 600,000 units annually, with 521,644 units in FY2019. Of these, the export ratio was $81.4 \%$ in FY2019.And the percentage of used motorcycles exported tends to be higher for those with $50 \mathrm{cc}$ and less total emissions, which was $62.8 \%$ in FY2019. In this section, we will discuss the number of exported used motorcycles categorized by emission volume and their specific destinations (export countries) from the Ministry of Finance's
"Trade Statistics of Japan" to examine the characteristics of Japan's motorcycle distribution flow.

Figure 5 displays changes in the number of exported used motorcycles categorized by emission volume from 2005 to 2019 [17]. This chart shows that motorcycles with total emissions of $50 \mathrm{cc}$ and less account for the largest percentage: $78.7 \%(343,152$ units) in $2005,85.8 \%(374,184)$ in 2006 , and $90.2 \%(393,359)$ in 2007 . However, these percentages rapidly decrease in 2008 (74.9\%, 326,778 units) and 2009 (58.9\%, 256,798 units). In 2010, it slightly recovered with $62.3 \%(271,546)$. Thereafter, they remained between 60.0 and $64.5 \%$, with $62.8 \%(273,690)$ in 2019 . Although this study speculated that global stagnation caused by the Lehman Brothers bankruptcy in 2008 was the primary factor for this drastic decline in 2009 , definite proof remains unknown.

Because HS codes were assigned to vehicles with electric motor for propulsion in January 2017, data from the Ministry of Finance Trade Statistics of Japan, in Fig. 5, shows electric two-wheel vehicle changes after 2016 as follows: 5560 units in 2016; 32,512 units in 2017; 44,401 units in 2018; and 49,283 units in 2019. Since numbers of "other" category units have declined during these years, it is presumed that "other" in previous years included "those with an electric motor for propulsion". Table 1 shows destinations (export countries) for electric two-wheel vehicles and specified the top ten recipient countries for cumulative shipments between 2016 and 2019. The volume of exports to Asian countries was distinctly larger based on this data. The year 2016 only includes 3 months of data from January to March 2017 [17].
Fig. 5 Number of exported used motorcycles categorized by emission volume

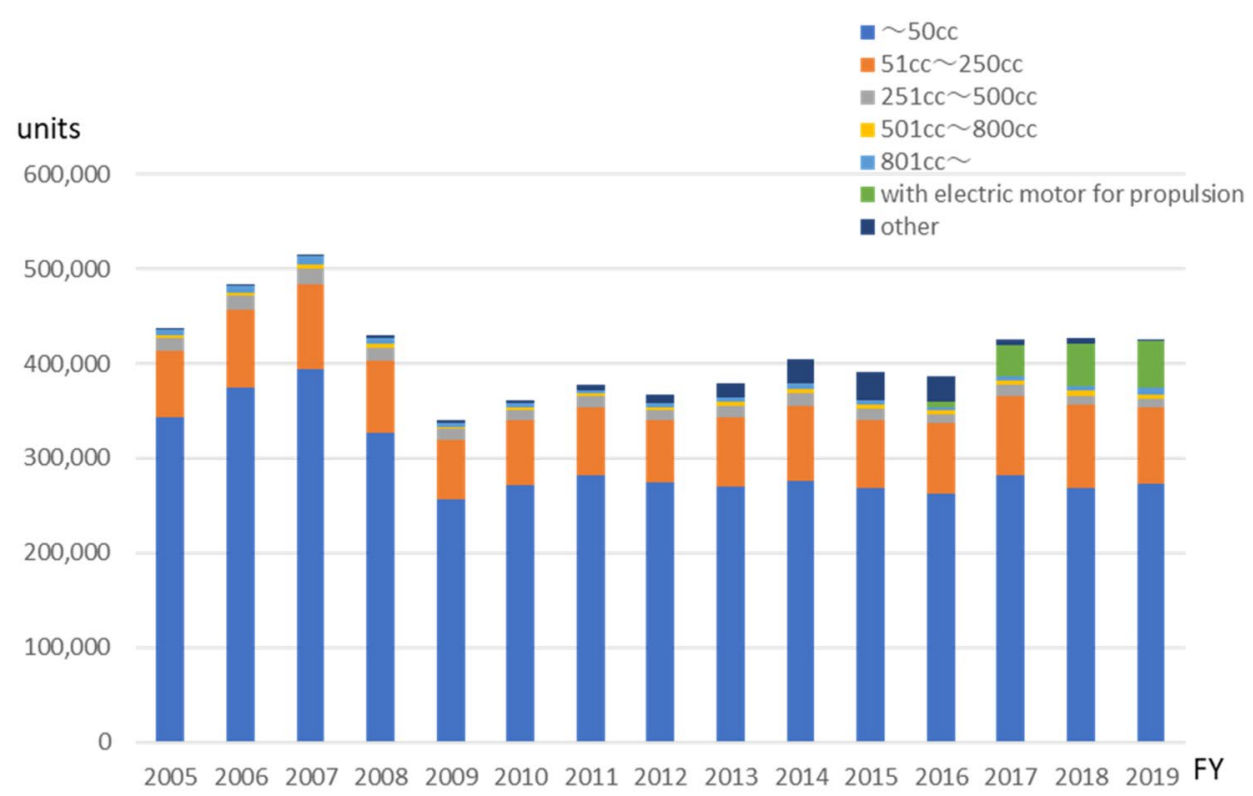


Table 1 Export countries of electric two-wheel vehicles [17]

\begin{tabular}{llllll}
\hline & 2016FY & 2017FY & 2018FY & 2019FY & Total \\
\hline Myanmar & 3264 & 23,694 & 29,035 & 33,369 & 89,362 \\
Cambodia & 984 & 4407 & 9870 & 12,996 & 28,257 \\
Hong Kong & 1263 & 3974 & 4426 & 2020 & 11,683 \\
Thailand & 49 & 272 & 100 & 181 & 602 \\
Iraq & NA & NA & 406 & 112 & 518 \\
Turkey & NA & NA & NA & 385 & 385 \\
UAE & NA & NA & 220 & NA & 220 \\
Sri Lanka & NA & 10 & 68 & 128 & 206 \\
Hungary & NA & NA & 170 & NA & 170 \\
China & NA & 130 & NA & 3 & 133 \\
\hline
\end{tabular}

This study compiled the specific destinations (export countries). Figure 6 indicates the top five cumulative shipments between 2005 and 2019. In 2005, the shipment to Ukraine was 113,113 units, comprising 33,982 units to Russia, 32,136 units to the UAE, 18,942 units to Cambodia, and 455 units to Iraq. In 2019, the shipment to Cambodia was 75,262 units, 65,217 units to Iraq, 49,179 units to Ukraine, 31,167 units to Russia, and 28,245 units to the UAE [17].

The study further examined changes in each country. In 2007, 134,008 units were shipped to Ukraine but were rapidly reduced to 9953 units in 2010 . The number subsequently increased to 22,687 units in 2011 and 39,518 units in 2012. Since then, the quantum of imports has fluctuated; however, a trend toward increases is recognized. Shipments to Russia increased to 71,021 units in 2007 but decreased to 37,234 units in 2009 . It again increased to 77,021 units in 2012 but continued to decrease to 13,133 units in 2015 . Since then, the volume has steadily increased. Shipments to the UAE decreased to 31,503 units in 2008 but increased to 55,676 units in 2009 . Subsequently, the volume periodically fluctuated. Although it decreased to 17,298 units in 2017, a trend favoring an increase is recognized. Shipments to Cambodia continued to increase as follows: 35,626 units in 2012; 50,008 units in 2013; and 61,002 units in 2014. In 2016, the volume decreased to 53,023 units; however, a trend showing an increase is now recognized. Finally, there was a continued annual increase in shipments to Iraq: 8901 units in 2011; 13,472 units in 2012; and 36,381 units in 2014. In 2015 , the volume rapidly increased to 71,384 units and further increased to 105,245 units in 2016. However, it decreased to 80,198 units in 2018.

This study cumulatively compared the top five countries and confirmed that imported units drastically fluctuated in Ukraine, Iraq, Russia, and the UAE. However, Cambodia maintained its stability without erratic fluctuations.

\section{The actors who form the industry}

The Japan Motorcycle Auction Association (subsequently called "the association"), where major motorcycle auction sites comprise its membership was interviewed to comprehend Japan's used motorcycle distribution flow. The association was established in 1992 to prevent motorcycle-related crimes, since the registration system for two-wheel vehicles did not yet exist. The association provides various services to auction site members. Furthermore, it developed and provided a "motorcycle mileage management system" in 2003 and a "theft-related information answering operation" in
Fig. 6 Top five cumulative export

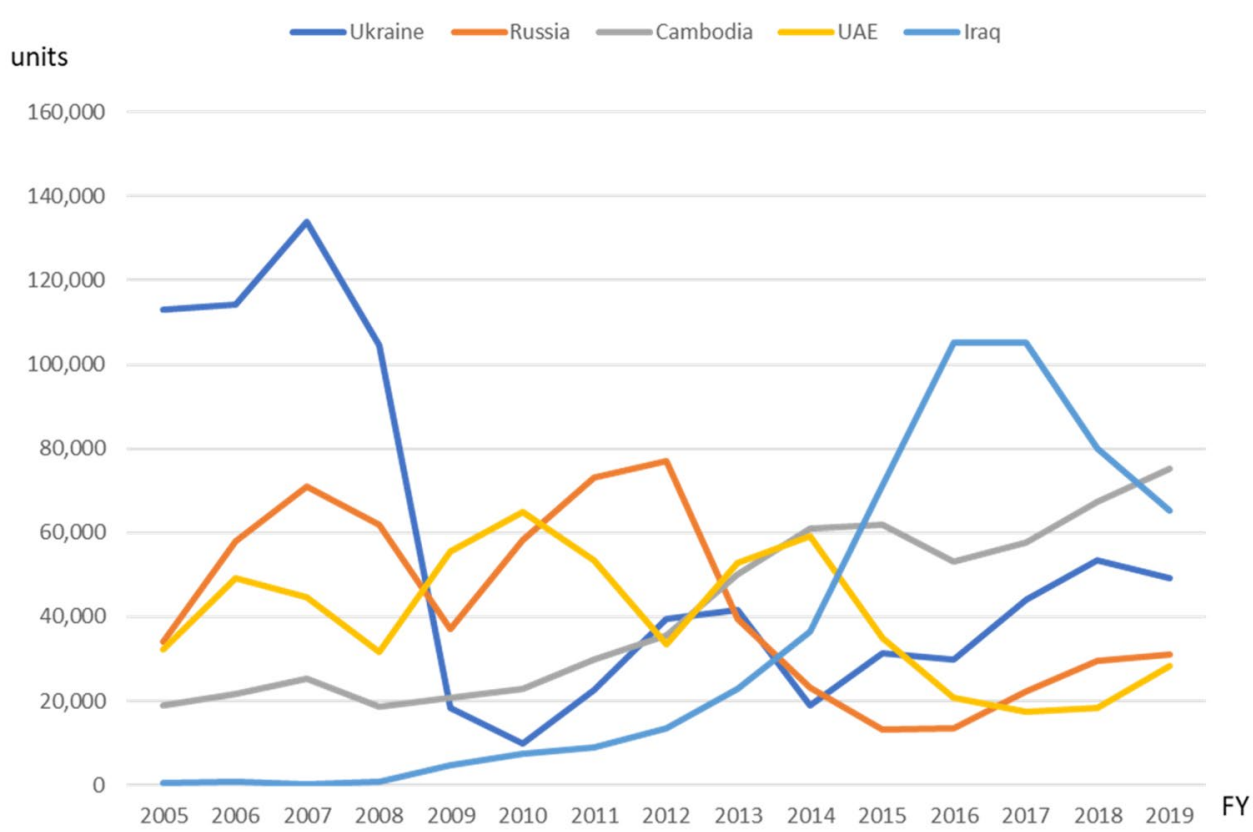


Fig. 7 Distribution flow and main actors

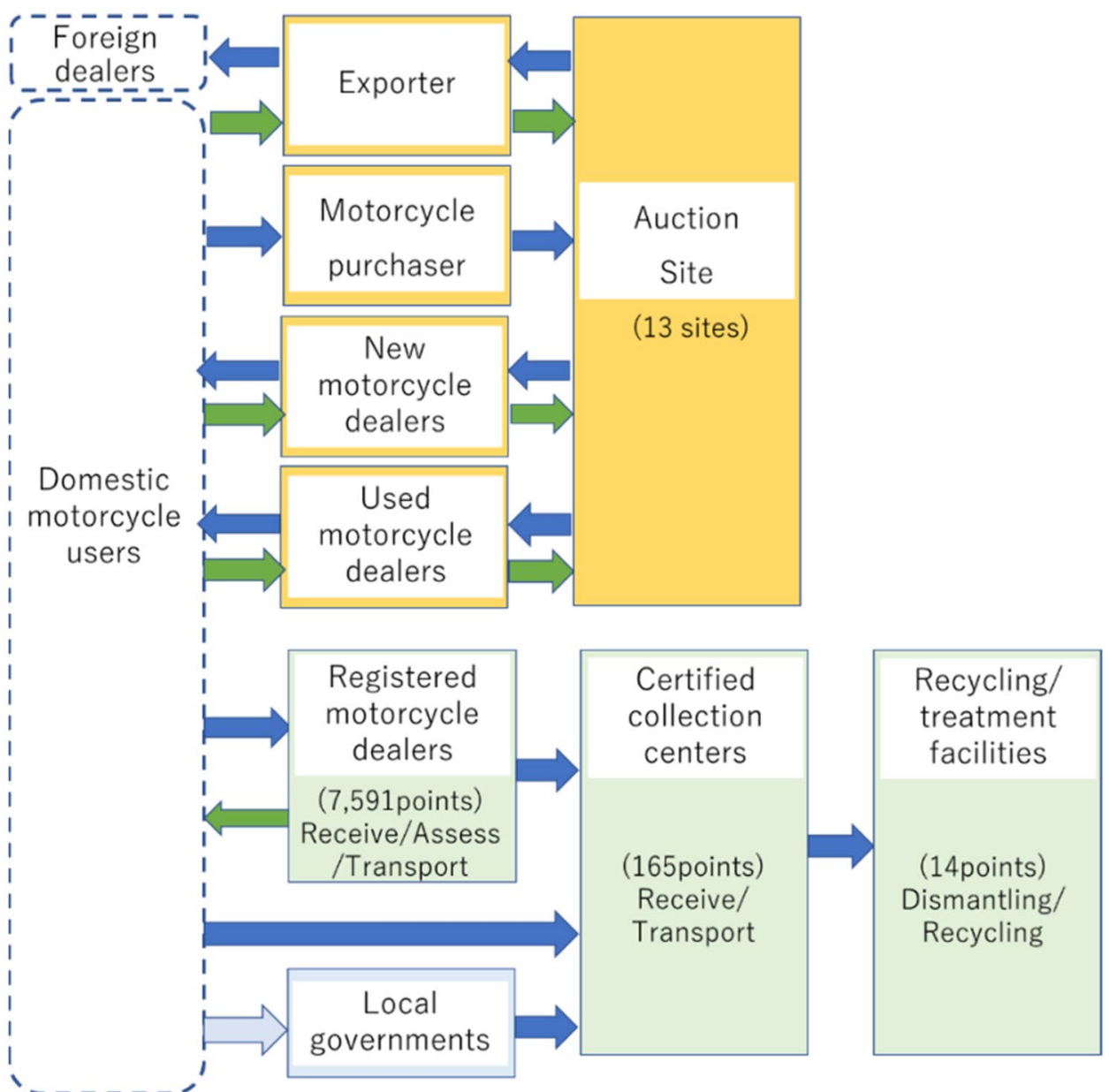

2005, enabling them to obtain stolen vehicle information using motorcycle identification numbers.

There are three auction types: those selling drivable motorcycles, others requiring dismantling, and internet auctions selling used parts.

Figure 7 shows the distribution flow, including the relationship between motorcycle dealers and auction sites. The lower part of Fig. 7 reflects the ELMCs flow that is also shown in Fig. 1. More precisely, Fig. 7 specifies the main actors in the Japanese ELMCs flow. The arrows in Fig. 7 indicate this flow. The blue arrows reflect the direction of the main actors' primary tasks, while the green arrows show the secondary tasks of the main actors (compared to the tasks of blue arrows).

In Fig. 7, auction exhibitors include exporters who export motorcycles, motorcycle purchasers who buy and sell at auctions and earn profits, dealers who sell new motorcycles and traded-in motorcycles, and dealers who purchase and sell used motorcycles. Auction bidders include exporters and new and used motorcycle dealers. The exporters export used motorcycles purchased at auctions.
According to the association, nine corporations manage 13 auction sites, and the total annual listings comprise approximately 450,000 motorcycles with total annual closing bids of 380,000. According to the association's director, "of the auction sites where primary listings are Class 1 and Class 2 motorcycles, approximately $90 \%$ of closed bids are assumed to be exported, although no such aggregation of data exists".

Distribution flow and main actors in Japan, reflected in Fig. 7, prove that auction sites stand in the position of redistributing used motorcycles into markets, and auction sites are assumed to be the main actors for ELMCs distribution flow.

\section{Conclusion}

This study's results clarified the following items:

1. The share of used motorcycle exports in ELMCs is large, reaching $81.4 \%$ (424,372 units) in 2019. 
2. Among used motorcycle export numbers in ELMCs, the number of motorcycles with total emissions of $50 \mathrm{cc}$ and less was sizable, reaching $62.8 \%$ (273,690 units) in 2019.

3. Auction sites are the core of used motorcycle distribution flow and are the main actors responsible for running the used motorcycle recycling system.

This study suggests several future challenges. First, because various factors of ELMCs' numbers remain undetermined, these factors must be analyzed by researching each domestic actor and changes in the legal systems of all export countries. Second, since the occurrence of secondary exports from these destination countries back to Japan is assumed, it is crucial to investigate distribution flows and clarify the characteristics and main actors in each destination country's distribution flow.

Acknowledgements We are grateful to everyone who gave their time and shared their experiences in the interviews for this research. We would also like to thank the two reviewers of our article for useful comments on first drafts, which helped us to improve the quality of the final submitted version. This work was supported by JSPS Grant-in-Aid for Scientific Research (B) Grant Number 19H01385.

Open Access This article is licensed under a Creative Commons Attribution 4.0 International License, which permits use, sharing, adaptation, distribution and reproduction in any medium or format, as long as you give appropriate credit to the original author(s) and the source, provide a link to the Creative Commons licence, and indicate if changes were made. The images or other third party material in this article are included in the article's Creative Commons licence, unless indicated otherwise in a credit line to the material. If material is not included in the article's Creative Commons licence and your intended use is not permitted by statutory regulation or exceeds the permitted use, you will need to obtain permission directly from the copyright holder. To view a copy of this licence, visit http://creativecommons.org/licenses/by/4.0/.

\section{References}

1. Yoneyama A, Matsumoto T (2010) A real-world example of EPR policies: recycling of motorcycle in Japan (in Japanese). Mater Cycles and Waste Manag Res 21:111-117. https://doi.org/10. 3985/mcwmr.21.111

2. Abe A, Kimura M (2017) Statistics on motorcycle recycling organize and consider (in Japanese). Mon Automob Recycl $81: 32-42$

3. Kimura M, Asazuma Y (2021) Used motorcycle recycling system-Japan motorcycle recycling system and related data (in Japanese). Bull Tokyo City Univ Yokohama Campus 8:25-35

4. Hara T (2018) Are the numbers of motorbike in use in Japan overevaluated? Statistics on stock-flow balance of motorbike in Japan
Revisited (in Japanese). J Life Cycle Assess Jpn 14:85-98. https:// doi.org/10.3370/lca.14.85

5. Murakami G, Kosai S, Kurogi D, Yamasue E (2020) Potential amount estimation of used motorcycle including electric motorcycle in Vietnam (in Japanese). In: Proceedings of the annual conference of Japan Society of Material Cycles and Waste Management 31:31-32. doi: https://doi.org/10.14912/jsmcwm.31.0_31

6. Government of Japan (1960, 2020 rev.) The Road Transport Vehicle Act (in Japanese). https://elaws.e-gov.go.jp/document?lawid= 326AC0000000185, Accessed October 9, 2021

7. Government of Japan (1951, 2020 rev.) The Enforcement Regulations of the Road Transport Vehicle Act (in Japanese). https://elaws.e-gov.go.jp/document?lawid=326M50000800074, Accessed October 9, 2021

8. Government of Japan (2002, 2017 rev.) The Act on Recycling, etc. of End-of-Life Vehicles (in Japanese). https://elaws.e-gov.go.jp/ document?lawid=414AC0000000087, Accessed October 9, 2021

9. Industrial Structure Council (2001) Second Report (Draft) (in Japanese). Association automobile recycling WG/Toward Constr New Automobile Recy Syst/Concept for Institutionalization of Automobile Recycling, http://www.mayors.or.jp/p_opinion/ documents/old/iken/h130827car/1honbun.pdf, Accessed October 9,2021

10. Industrial Structure Council (2004) Document 8 (in Japanese). Industrial Structure Council Environment Subcommittee Waste/ Recycling Subcommittee Automobile Recycling WG Central Environment Council Waste/Recycling Subcommittee Automobile Recycling Expert Committee 7 July 2004 7st Joint Meeting, https://www.meti.go.jp/shingikai/sankoshin/sangyo_gijutsu/haiki butsu_recycle/jidosha_wg/pdf/g40712a80j.pdf, Accessed October 9,2021

11. Japan Automobile Recycling Promotion Center (in Japanese). https://www.jarc.or.jp/motorcycle/faq/, Accessed October 9, 2021

12. Industrial Structure Council (2003) Document 8 (in Japanese). Industrial Structure Council Environment Subcommittee Waste/ Recycling Subcommittee Automobile Recycling WG Central Environment Council Waste/Recycling Subcommittee Automobile Recycling Expert Committee 3 December 2003 5th Joint Meeting, https://www.meti.go.jp/shingikai/sankoshin/sangyo_gijutsu/haiki butsu_recycle/jidosha_wg/pdf/005_08_00.pdf, Accessed October 9,2021

13. Automobile Inspection \& Registration Information Association (in Japanese). https://www.airia.or.jp/info/system/02.html, Accessed October 9, 2021

14. Kanto District Transport Bureau (in Japanese). https://wwwtb. mlit.go.jp/kanto/jidou_gian/touroku/motor_regist.html, Accessed October 9, 2021

15. Japan Automobile Manufacturers Association (2019) World Motor Vehicle Statistics Annual Report 18 (in Japanese)

16. Abe A (2014) Review of Statics Related to End-of-life Vehicles in Japan (in Japanese). Bulletin of the Faculty of Education, Yamaguchi University 63:1-9. http://petit.lib.yamaguchi-u.ac.jp/G0000 006y2j2/metadata/C030063000101, Accessed October 9, 2021

17. Trade Statics of Japan (in Japanese). https://www.customs.go.jp/ toukei/info/, Accessed October 9, 2021

Publisher's Note Springer Nature remains neutral with regard to jurisdictional claims in published maps and institutional affiliations. 